\title{
Correction \\ Correction: Jun et al. Improvement of Osseointegration by Ultraviolet and/or Simvastatin Treatment on Titanium Implants with or without Bone Graft Materials. Materials 2021, 14, 3707
}

\author{
Ji Hoon Jun ${ }^{1,2}{ }^{\mathbb{D}}$, Kyung Chul Oh ${ }^{1}\left(\mathbb{D}\right.$, Kyu-Hyung Park $^{3}$, Narae Jung ${ }^{3}$, Jiayi Li ${ }^{1}$ and Hong Seok Moon ${ }^{1, *(D)}$ \\ 1 Department of Prosthodontics, Yonsei University College of Dentistry, Seoul 03722, Korea; \\ jhjun0103@yonsei.ac.kr (J.H.J.); kyungabc@yuhs.ac (K.C.O.); ljyzoeli24@gmail.com (J.L.) \\ 2 Aeromedical Squadron, Republic of Korea Air Force 8th Fighter Wing, Wonju 26304, Korea \\ 3 Oral Science Research Center, BK21 Plus Project, Yonsei University College of Dentistry, Seoul 03722, Korea; \\ khyungpark@gmail.com (K.-H.P.); jnrgood1217@yuhs.ac (N.J.) \\ * Correspondence: hsm5@yuhs.ac; Tel.: +82-2-2228-3155; Fax: +82-2-312-3598
}

check for updates

Citation: Jun, J.H.; Oh, K.C.; Park, K.-H.; Jung, N.; Li, J.; Moon, H.S.

Correction: Jun et al. Improvement of Osseointegration by Ultraviolet and/or Simvastatin Treatment on Titanium Implants with or without Bone Graft Materials. Materials 2021, 14, 3707. Materials 2022, 15, 1293. https://doi.org/10.3390/ma1504 1293

Received: 27 January 2022 Accepted: 29 January 2022 Published: 10 February 2022

Publisher's Note: MDPI stays neutral with regard to jurisdictional claims in published maps and institutional affiliations.

Copyright: () 2022 by the authors. Licensee MDPI, Basel, Switzerland. This article is an open access article distributed under the terms and conditions of the Creative Commons Attribution (CC BY) license (https:// creativecommons.org/licenses/by/ $4.0 /)$.

\section{Additional Affiliation}

In the published publication [1], there was an error regarding the affiliations for Ji Hoon Jun. In addition to affiliation 1, "Aeromedical Squadron, Republic of Korea Air Force 8th Fighter Wing, Wonju 26304, Korea" should be added. The corrected affiliation appears above.

The authors apologize for any inconvenience caused and state that the scientific conclusions are unaffected. The original publication has also been updated.

\section{Reference}

1. Jun, J.H.; Oh, K.C.; Park, K.-H.; Jung, N.; Li, J.; Moon, H.S. Improvement of Osseointegration by Ultraviolet and/or Simvastatin Treatment on Titanium Implants with or without Bone Graft Materials. Materials 2021, 14, 3707. [CrossRef] [PubMed] 